\title{
Effect of antihistamines and antiallergic drugs on responses to allergen and histamine provocation tests in asthma
}

\author{
MJ PHILLIPS, S OLLIER, CAL GOULD, RJ DAVIES \\ From the Academic Unit of Respiratory Medicine, St Bartholomew's Hospital, London
}

\begin{abstract}
The inhibition of immediate allergen or histamine induced airflow obstruction by inhaled ketotifen, clemastine, sodium cromoglycate, and placebo was studied in two groups of asthmatic subjects. Single doses of ketotifen $(0.5 \mathrm{mg})$, clemastine $(0.5 \mathrm{mg})$, sodium cromoglycate $(20 \mathrm{mg})$, or placebo were administered by inhalation 45 minutes before bronchial provocation testing at weekly intervals, double blind and in random order. Inhalation of ketotifen and clemastine, but not sodium cromoglycate, caused an increase in the amount of histamine which had to be administered to cause a $20 \%$ fall in $\mathrm{FEV}_{1}$ from control levels $\left(\mathrm{PD}_{20-\mathrm{FEV}}\right)$ compared with placebo. The $\mathbf{P D}_{20-\mathrm{FEV}_{1}}$ for allergen increased significantly after inhalation of clemastine and sodium cromoglycate. Clemastine, primarily an $\mathrm{H}_{1}$ receptor antagonist, inhibited airflow obstruction after inhalation of both histamine and allergen. Its inhibitory effect on allergen induced asthma did not differ significantly from that of sodium cromoglycate. Ketotifen, when inhaled in a single dose of $0.5 \mathrm{mg}$ before bronchial provocation testing, showed potent antihistamine activity, but there was no evidence of any additional "antianaphylactic" activity.
\end{abstract}

Ketotifen was recently introduced as an oral antiasthmatic agent. Martin and Römer, ${ }^{1}$ on the basis of animal and in vitro studies, showed that it possessed antihistaminic properties but not antiserotonin or anticholinergic effects. They also claimed that it possessed additional antianaphylactic properties. It inhibited $48 / 80$ of the induced release of histamine from rat peritoneal mast cells and inhibited the Prausnitz-Kustner reaction in rat skin; whereas clemastine, an antihistamine, did not. Both clemastine and ketotifen inhibited the allergen induced rise in airways resistance in rats, but ketotifen was 90 times more potent than clemastine. Martin and Römer concluded that ketotifen had actions similar to sodium cromoglycate in stabilising mast cells with inhibition of mediator release. There were, however, differences between the two drugs. Ketotifen did not inhibit allergen induced histamine release from rat peritoneal mast cells, whereas sodium cromoglycate produced a dose dependent inhibition. The phenomenon of cross tachyphylaxis has also

Address for reprint requests: Dr RJ Davies, Academic Unit of Respiratory Medicine, St Bartholomew's Hospital, London EC1A 7BE.

Accepted 29 November 1983 been used as a means of recognising drugs with actions similar to those of sodium cromoglycate, ${ }^{2}$ but ketotifen did not show this effect.

Orally administered ketotifen has been shown to be better than placebo in several double blind studies of the treatment of asthma in children. ${ }^{34}$ In adults, however, not all studies have shown such a beneficial effect. ${ }^{5}$ In this study we have evaluated the mode of action of ketotifen by comparing its effects with those of clemastine, sodium cromoglycate, and placebo in histamine and allergen bronchial tests. All the drugs were administered by the inhaled route. Previous studies with ketotifen in asthmatic subjects have used the oral route of administration, often comparing its effectiveness when given in this manner with sodium cromoglycate administered by inhalation and so making valid comparisons difficult.

\section{Methods}

\section{SUBJECTS}

Two groups of atopic asthmatic subjects were studied. Ten subjects, five female and five male (age range 21-57 years), had histamine provocation tests and the other nine subjects, three female and six 
male (age range 16-43 years), had allergen provocation tests. All subjects had relatively mild asthma, which was adequately controlled with intermittent inhaled $\beta$ adrenoceptor stimulants alone, and had a forced expiratory volume in one second $\left(\mathrm{FEV}_{1}\right)$ of over $70 \%$ of their predicted value when not taking any medication. All subjects in the allergen group had a positive skinprick test reaction to house dust mite (Dermatophagoides pteronyssinus). None of the subjects had received oral or inhaled steroids or sodium cromoglycate during the month before the study, and none was taking antihistamines. Subjects requiring the intermittent use of inhaled salbutamol for control of their asthma took none of this medication in the 24 hour period immediately before each provocation test. No subject was entered into the study within four weeks of an upper respiratory tract infection, and subjects were withdrawn from the study if symptoms consistent with a respiratory tract infection developed during the study. Subjects with seasonal asthma were studied outside the hay fever season, and in all subjects asthmatic symptoms and responses to respiratory function tests remained stable during the study period. The study was approved by the hospital ethical committee and every subject gave written, informed consent to participation in the study.

\section{PROVOCATION SOLUTIONS AND METHODS OF DELIVERY}

Phenol saline solution $(0.4 \%$ weight to volume $(\mathrm{w} / \mathrm{v})$ phenol, $0.275 \% \mathrm{w} / \mathrm{v}$ sodium bicarbonate in $0.5 \%$ saline) was used as the control. Histamine acid phosphate solution was prepared each week at concentrations of $0 \cdot 5,1 \cdot 0,2 \cdot 5,5 \cdot 0,10 \cdot 0,25 \cdot 0 \mathrm{mg} / \mathrm{ml}$. Glycerinated allergen solutions of $D$ pteronyssinus were obtained from Bencard (Brentford, UK) and were dialysed against phenol saline to obtain sufficient stock material to test each individual subject throughout the study. Allergen solutions were prepared from stock each week by dilution in phenol saline to concentrations of 1:10000, 1:5000, $1: 1000$ and $1: 100 \mathrm{w} / \mathrm{v}$.

All solutions were administered via a de Vilbiss 646 nebuliser attached to a Rosenthal-French dosimeter. ${ }^{6}$ The dosimeter consisted of a breath activated solenoid valve and a source of compressed air at $20 \mathrm{lb} / \mathrm{in}^{2}(138 \mathrm{kPa})$. Once activated the valve remained open for $0 \cdot 6$ seconds. Subjects were instructed to take a slow inhalation from functional residual capacity (FRC) to total lung capacity (TLC) and to hold their breath for five seconds at the end of each inhalation. They were asked to take five breaths of each provocation solution before measurement of airway response.
HISTAMINE AND ALLERGEN BRONCHIAL PROVOCATION TESTING

Responses to provocation were monitored by following changes in FEV 1 with a dry bellows spirometer (Vitalograph Ltd, Maids Moreton, Bucks).

After measurement of baseline $F E V_{1}$ the control solution was administered and $\mathrm{FEV}_{1}$ recorded at 30 seconds, 90 seconds, three minutes, and five minutes in the patients due to receive the histamine bronchial provocation and at $\mathbf{3 0}$ seconds, five minutes, and 10 minutes in the group due to receive the allergen bronchial provocation. If inhalation of the control solution resulted in a fall in $\mathrm{FEV}_{1}$ of more than $10 \%$ from the initial value further provocation testing was abandoned. If the $\mathrm{FEV}_{1}$ remained above $90 \%$ of the baseline value the most dilute provocation solution was administered.

$\mathrm{FEV}_{1}$ was measured at 30 seconds, 90 seconds, three minutes, and five minutes after inhalation of histamine, and if necessary at two minute intervals thereafter until the maximum fall in $\mathrm{FEV}_{1}$, had been passed. Further histamine solutions were given in increasing concentrations until a fall in $\mathrm{FEV}_{1}$ of $20 \%$ or more from the lowest post control value was obtained. Two puffs of salbutamol aerosol were then administered to help reverse the airflow obstruction.

The initial concentration of allergen solution inhaled by each subject was determined by skinprick testing. All concentrations of $D$ pteronyssinus extract were skinprick tested in duplicate on the volar surface of the forearm. The concentration resulting in a weal of $3 \mathrm{~mm}$ or less was used as the initial allergen solution for provocation testing. After administration of the first allergen solution measurements of $F E V_{1}$ were made at 30 seconds, five minutes, and 10 minutes after the challenge, and if necessary at further five minute intervals until the $\mathrm{FEV}_{1}$ began to return to the prechallenge level. Allergen solutions of increasing concentration were administered until a fall in $\mathrm{FEV}_{1}$ of $20 \%$ or more from the lowest post control value had been recorded. On completion of the test each subject was asked to inhale two puffs of salbutamol aerosol to reverse any remaining airflow obstruction and four puffs of beclomethasone dipropionate aerosol to reduce the possibility of late asthmatic reactions. All subjects were advised to take regular inhalations of $200 \mu \mathrm{g}$ of salbutamol and $100 \mu \mathrm{g}$ of beclomethasone dipropionate at four hourly intervals for the remainder of each study day

\section{ADMINISTRATION OF DRUGS}

The three drugs and placebo solutions were administered via the nebuliser in the same way as the histamine and allergen solutions. The drug concentrations used were: ketotifen $0.5 \mathrm{mg} / \mathrm{ml}$, clemastine 


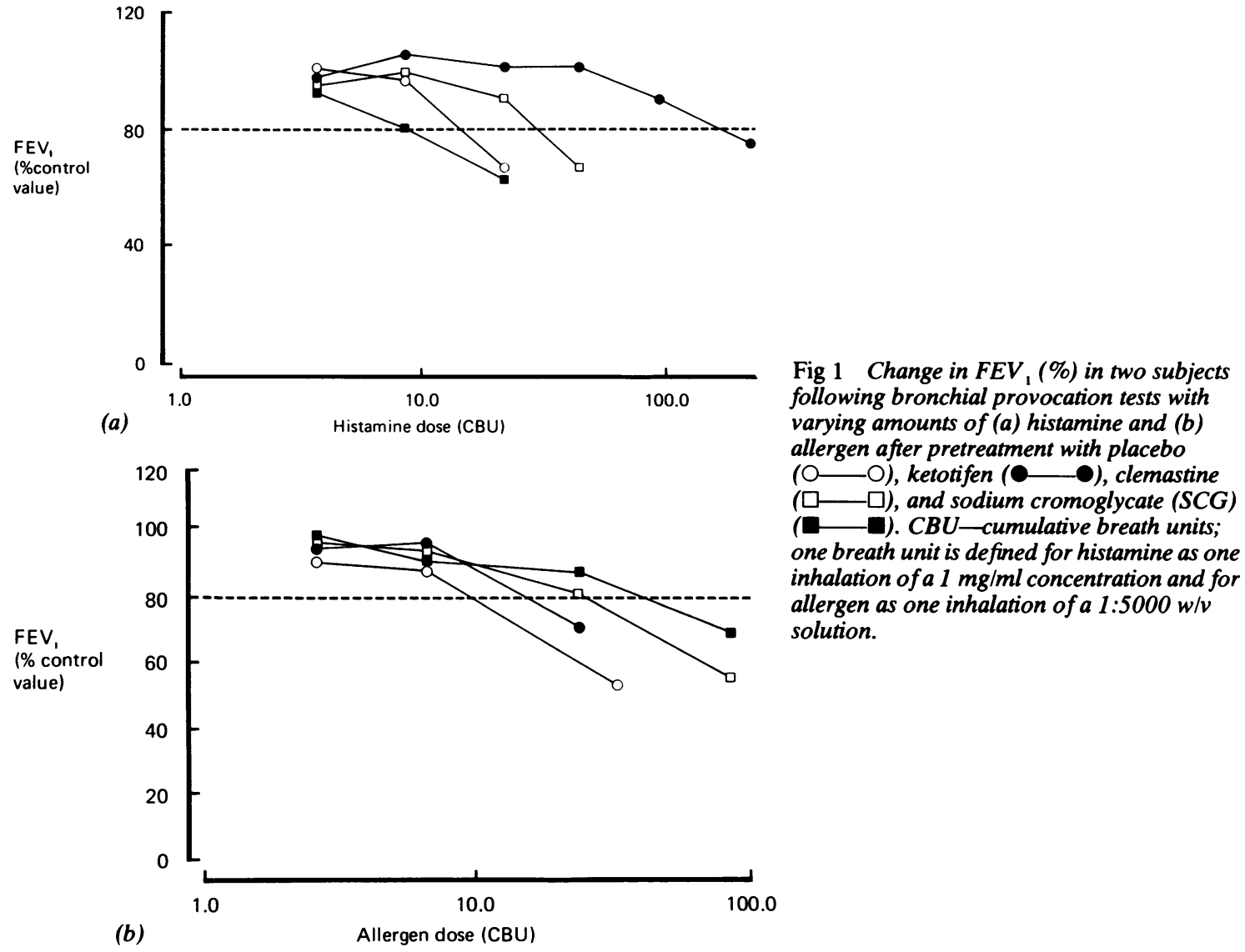

$0.5 \mathrm{mg} / \mathrm{ml}$, and sodium cromoglycate $20 \mathrm{mg} / \mathrm{ml}$, with $0.9 \%$ saline as placebo. Subjects were asked to continue taking breaths from functional residual capacity (FRC) until $1 \mathrm{ml}$ of drug had left the nebuliser. Each drug was administered 45 minutes before bronchial provocation testing and the $\mathrm{FEV}_{1}$ was measured immediately before inhalation of the drug and at intervals of $0 \cdot 5,5,10,15,30$, and 45 minutes thereafter.

\section{STUDY DESIGN AND STATISTICAL ANALYSIS}

Bronchial provocation tests were performed double blind and in random order at intervals of one week after inhalation of drug or placebo.

A cumulative dose response curve was constructed for each of the histamine and allergen challenges by plotting cumulative breath units (CBU) logarithmically on the abscissa against $\mathrm{FEV}_{1}$, as percentages of the control values, on the ordinate. Examples of this for individual subjects are shown in figure 1. One breath unit of histamine is defined as one inhalation of a $1 \mathrm{mg} / \mathrm{ml}$ concentration of the agonist, and an allergen breath unit as one inhalation of a 1:5000 w/v solution of the allergen. ${ }^{6}$ The results of provocation testing were expressed as the number of cumulative breath units of either allergen or histamine required to produce a $20 \%$ fall in the $\mathrm{FEV}_{1}$ from the lowest value that followed inhalation of the control solution-the $\mathrm{PD}_{20-\mathrm{FEV}}$. Figure 1 shows the results of bronchial provocation tests with allergen and histamine in two subjects and the effect of drugs and placebo on the response. On 12 occasions during histamine testing and one occasion during allergen testing it was not possible to produce a fall in $\mathrm{FEV}_{1}$ of $20 \%$ or more despite administration of the highest concentration of agonist available because of the highly effective inhibitory action of the administered drugs. In these circumstances an artificial value had to be given for the $\mathrm{PD}_{20-\mathrm{FEV}}$ (5000 CBU) to allow calculation of median values and enable Friedman's analysis of variance ${ }^{7}$ on the ranked results and the sign test to be carried out. The value given for the $P D_{20-F E v}$ when no actual value was obtained is immaterial for ranking pur- 
poses provided that it is greater than the highest recorded value. The reproducibility of both allergen and histamine bronchial provocation was studied in two groups of five asthmatic subjects. The $P_{20-F E v}$ for either allergen or histamine was obtained on four separate weekly occasions for each subject in the group. Since the results obtained were not normally distributed the coefficient of variation was calculated with the logarithms of the data and the standard deviation around the geometric mean.

\section{Results}

There was no significant variation in the mean FEV, for the subjects before bronchial provocation testing on any of the four study days, as seen from table 1 , which also shows the effects of administration of saline and each of the drugs on the $\mathrm{FEV}_{1}$ before histamine or allergen provocation in all subjects. One subject in the allergen provocation group developed an upper respiratory tract infection during the course of the study and had to be withdrawn from the investigation, leaving 18 subjects. No drug

Table $1 F E V$, values (means with standard deviations in parentheses) for all 18 subjects before drug inhalation on each of the four study days and after inhalation of placebo, ketotifen, clemastine, or sodium cromoglycate

\begin{tabular}{lll}
\hline & $F E V_{1}(l)$ \\
\cline { 2 - 3 } & Before inhalation & After inhalation \\
\hline Placebo & $3.53(0 \cdot 18)$ & $3.58(0.16)$ \\
Ketotifen & $3.41(0.17)$ & $3.68(0.18)$ \\
Clemastine & $3.51(0.17)$ & $3.67(0.17)$ \\
Sodium cromoglycate & $3.42(0.12)$ & $3.57(0.16)$ \\
\hline
\end{tabular}

None of the differences between the values before and after inhalation was significant. resulted in any significant increase in $\mathrm{FEV}_{1}$ at any time during the 45 minutes after inhalation. The studies of the reproducibility of the results of allergen and histamine bronchial provocation tests showed a mean coefficient of variation of the $\mathrm{PD}_{20 \text {-FEV }}$ for each group of five subjects on the four weekly occasions of $19.3 \%$ for the allergen provocation tests and $17.5 \%$ for the histamine provocation tests.

Individual $\mathrm{PD}_{20-\mathrm{FEV}}$ values after histamine and allergen inhalation with median values are shown in table 2. The effects of the drugs on histamine provocation for the group as a whole are illustrated in figure 2. After pretreatment with ketotifen and clemastine the $P_{20}-\mathrm{FEV}$ was significantly higher than after placebo $(\mathrm{p}<0.002)$. There was no significant difference in the $\mathrm{PD}_{20 \text {-FEv }}$ values for histamine after pretreatment with sodium cromoglycate and placebo.

The results for the eight subjects in the allergen group are displayed in figure 3 . Pretreatment with ketotifen, clemastine, and sodium cromoglycate resulted in high $\mathrm{PD}_{20-\mathrm{FEV}}$ values, though only the effects of clemastine and sodium cromoglycate were significant $(p<0.035)$ by comparison with placebo. The differences between the effects of ketotifen, clemastine, and sodium cromoglycate on allergen inhalation were not significant.

\section{Discussion}

In this study no significant degree of bronchodilatation or bronchoconstriction resulted from the inhalation of single doses of ketotifen $(0.5 \mathrm{mg})$, clemastine $(0.5 \mathrm{mg})$, or sodium cromoglycate $(20 \mathrm{mg})$, nor was there any significant variation in the $\mathrm{FEV}_{1}$ of the subjects before drug or placebo administration. The

Table $2 P D_{20-F E V}$ values for allergen and histamine in cumulative breath units ${ }^{*}$ for each subject with medians for the two groups

\begin{tabular}{|c|c|c|c|c|c|c|c|c|c|c|}
\hline \multicolumn{5}{|c|}{$P D_{20-F E V_{1}}$ histamine* } & \multicolumn{5}{|c|}{$P D_{20-F E V_{1}}$ allergen* } & \\
\hline Subject No & Placebo & Ketotifen & Clemastine & $S C G$ & Subject No & Placebo & Ketotifen & Clemastine & $S C G$ & \\
\hline $\begin{array}{r}1 \\
2 \\
3 \\
4 \\
5 \\
6 \\
7 \\
8 \\
9 \\
10\end{array}$ & $\begin{array}{r}25 \cdot 0 \\
26 \cdot 0 \\
76 \cdot 0 \\
74.0 \\
165 \cdot 0 \\
6 \cdot 2 \\
40 \cdot 0 \\
9 \cdot 4 \\
14.0 \\
26.0\end{array}$ & $\begin{array}{c}5000 \dagger \\
5000 \dagger \\
5000 \dagger \\
5000 \dagger \\
5000 \dagger \\
270 \cdot 0 \\
5000 \dagger \\
160 \cdot 0 \\
175 \cdot 0 \\
5000 \dagger\end{array}$ & $\begin{array}{c}5000 \dagger \\
5000 \dagger \\
5000 \dagger \\
500 \dagger^{\dagger} \\
105 \cdot 0 \\
75 \cdot 0 \\
500 \dagger^{\circ} \\
177 \cdot 0 \\
29 \cdot 5 \\
190 \cdot 0\end{array}$ & $\begin{array}{r}27.0 \\
37.0 \\
5.0 \\
130.0 \\
25 \cdot 5 \\
12.3 \\
83.0 \\
6.4 \\
8.8 \\
2.7\end{array}$ & $\begin{array}{l}1 \\
2 \\
3 \\
4 \\
5 \\
6 \\
7 \\
8\end{array}$ & $\begin{array}{r}11 \cdot 0 \\
3 \cdot 9 \\
37 \cdot 0 \\
26 \cdot 5 \\
40 \cdot 0 \\
165 \cdot 0 \\
43 \cdot 0 \\
6.4\end{array}$ & $\begin{array}{r}21.0 \\
11.5 \\
350.0 \\
170.0 \\
35.0 \\
37.5 \\
125.0 \\
96.0\end{array}$ & $\begin{array}{r}35.0 \\
30.3 \\
330.0 \\
5000 \dagger \\
59 \cdot 0 \\
41.0 \\
65.5 \\
36.5\end{array}$ & $\begin{array}{r}50.0 \\
18.0 \\
390.0 \\
38.0 \\
145.0 \\
110.0 \\
115.0 \\
98.0\end{array}$ & 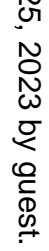 \\
\hline Median & $33 \cdot 0$ & $222 \cdot 5$ & $141 \cdot 0$ & $18 \cdot 9$ & Median & $31 \cdot 8$ & $66 \cdot 8$ & 50.0 & $104 \cdot 0$ & \\
\hline
\end{tabular}

*The number of cumulative breath units of allergen or histamine required to produce a $20 \%$ fall in FEV (PD 20 -FEV) from the lowest value following inhalation of the control solution; one breath unit is defined for histamine as one inhalation of a $1 \mathrm{mg} / \mathrm{ml}$ corlcentration and for allergen as one inhalation of a $1: 5000 \mathrm{w} / \mathrm{v}$ solution.

$\lceil 5000$ is an artificial value assigned for statistical ranking - see under "Study design and statistical analysis."

SCG-sodium cromoglycate. 


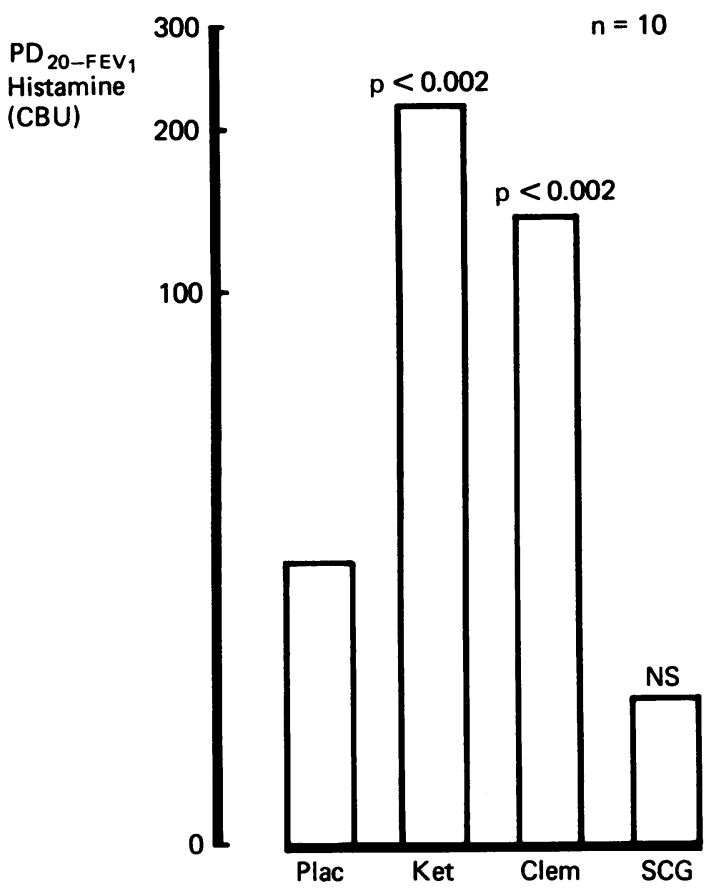

Fig 2 Effect of pretreatment with placebo, ketotifen, clemastine and sodium cromoglycate on median $P D_{20-F E V}$ values for histamine in 10 subjects. The results are expressed on a logarithmic scale. Plac-placebo; Ket-ketotifen; Clem-clemastine; SCG-sodium cromoglycate; $P D_{20-F E V} \rightarrow$ the number of cumulative breath units $(C B U)$ of histamine or allergen required to produce a $20 \%$ fall in $F E V$, from the lowest value following inhalation of the control solution.

$\mathrm{PD}_{20-\mathrm{FEV}}$ for histamine was increased by both ketotifen and clemastine, indicating an inhibitory effect on airflow obstruction induced by histamine. Clemastine and sodium cromoglycate caused a smaller though significant increase in the $P D_{20-F E v}$ for allergen.

The technique of bronchial provocation testing with both allergen and histamine has been criticised on the basis of the poor reproducibility of the results. Juniper and coworkers have shown excellent reproducibility of the responses in repeated bronchial provocation tests with histamine and methacholine when testing was performed on separate days within one week. ${ }^{8}$ The day to day variation in the airway response to allergen inhalation may be as high as tenfold ${ }^{9}$ and to our knowledge no one has studied the reproducibility of allergen provocation tesing at weekly intervals. It is necessary, in our opinion, to allow at least a week between bronchial

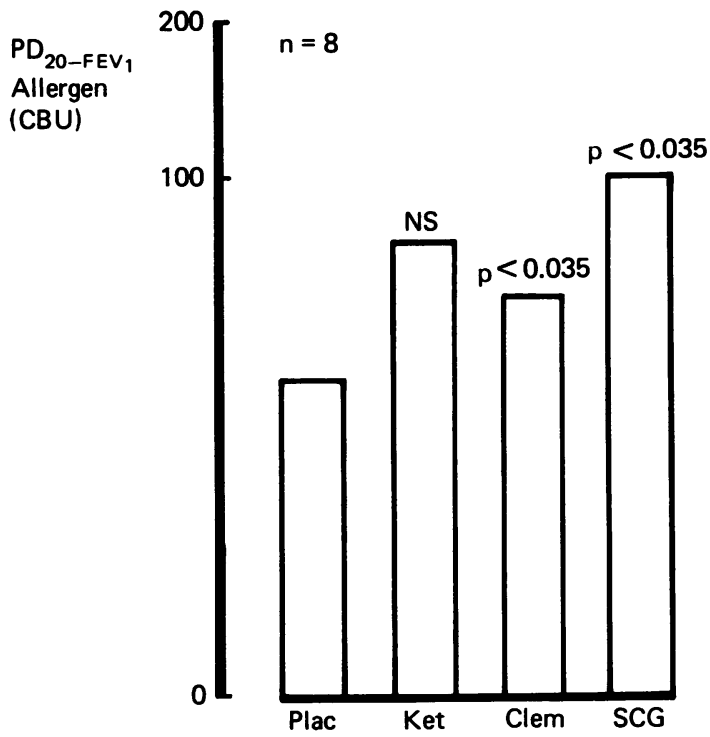

Fig 3 Effect of pretreatment with placebo, ketotifen, clemastine, and sodium cromoglycate on median $P D_{20-F E V}$ for allergen in eight subjects (abbreviations and scale as in fig 2).

provocation tests with allergen to reduce the effect of changes in non-specific bronchial reactivity which may occur after allergen inhalation, particularly when this is followed by a late reaction. ${ }^{10}$ We found that the variability in the responses to repeated bronchial provocation tests was $19.3 \%$ with allergen and $17.5 \%$ with histamine when the tests were performed at weekly intervals. Despite this degree of variability both ketotifen and clemastine produced highly significant inhibition of histamine induced bronchoconstriction and clemastine and sodium cromoglycate inhibited allergen induced bronchoconstriction when inhaled 45 minutes before provocation testing. The time of 45 minutes was chosen because this is the time when these drugs cause maximum inhibition of histamine and allergen induced weals in human skin. ${ }^{11}$

Previous studies have suggested that inhaled antihistamines may cause bronchodilatation. Nogrady et al $^{12}$ showed a $21 \%$ increase in $\mathrm{FEV}_{1}$ after inhalation of clemastine, but this was recorded in patients in hospital recovering from exacerbation of their asthma. These results were not confirmed by Partridge and Saunders, ${ }^{13}$ who found that clemastine was not a useful bronchodilator in a group of clinically stable asthmatics. The different results in these studies and in our own may be due to the varying degrees of severity of the airflow obstruction before 
treatment. Clemastine may not have had a bronchodilating effect in our subjects because the initial FEV 1 was over $70 \%$ of the mean predicted for sex, age, and height, leaving little opportunity for further bronchodilatation.

It has been shown previously that bronchoconstriction induced by histamine can be inhibited by oral antihistamines. ${ }^{14}$ In our study we used inhaled clemastine, a specific $\mathrm{H}_{1}$ receptor agonist, ${ }^{15}$ in the highest concentration which could be administered without causing pharyngeal irritation, which was similar to the concentration used in previous studies. ${ }^{12}$ At this dose of $0.5 \mathrm{mg}\left(1.087 \times 10^{-6} \mathrm{~mol}\right)$ inhaled clemastine significantly inhibited histamine induced bronchoconstriction-a result in agreement with the findings of Nogrady and Bevan. ${ }^{16} \mathrm{~A}$ higher median value of $\mathrm{PD}_{20-\mathrm{FEV}}$ for histamine occurred after inhalation of ketotifen at a molar equivalent dose of $0.5 \mathrm{mg}\left(1.175 \times 10^{-6} \mathrm{~mol}\right)$, reflecting the powerful antihistaminic activity of this drug, which we have previously shown in studies of the human skin. " Our results with inhaled ketotifen confirm the conclusions of other groups investigating the activity of oral ketotifen on histamine induced airflow obstruction. ${ }^{17} 18$

Sodium cromoglycate is considered to be a drug with no direct bronchodilator activity which is thought to act by inhibiting mediator release from human lung mast cells ${ }^{19}$-although compounds with more potent biological activity on mast cells have shown little efficacy in clinical studies. ${ }^{20}$ It has been argued that the clinical effects of sodium cromoglycate may not result from mast cell "stabilising" properties. Kerr and coworkers ${ }^{21}$ showed that the fall in $F E V_{1}$ produced by intravenous infusion of histamine in asthmatic subjects was inhibited by sodium cromoglycate and suggested that the drug might be acting directly on bronchial smooth muscle. Inhaled sodium cromoglycate, in the normal therapeutic dose of $20 \mathrm{mg}$, in our study did not inhibit airflow obstruction induced by histamine, which is in agreement with the results of Kang et al. ${ }^{22}$

Antihistamines are rarely used in the treatment of asthma and clinical experience has proved disappointing. ${ }^{23}$ Many studies have, however, used antihistamines with relatively weak potency administered in small doses, since higher doses given orally have produced unacceptably severe sedation. ${ }^{24}$ The value of antihistamines in the treatment of asthma is, however, being reassessed since inhalation allows high concentrations to be achieved locally without unwanted effects. In this study inhaled clemastine significantly inhibited allergen induced asthma, in keeping with the finding of Eiser and coworkers ${ }^{25}$ that intravenous chlorpheniramine $(20 \mathrm{mg})$ inhi- bited allergen induced bronchoconstriction in nine subjects with atopic asthma.

In common with many investigators, we found that sodium cromoglycate inhibited the response of the lung airways to inhaled allergen. This effect was not associated with any bronchodilator or antihistaminic activity.

Although ketotifen increased the amount of allergen required to produce a $20 \%$ fall in $\mathrm{FEV}_{1}$ in some subjects, the overall effect was not significantly different from that of placebo $(p=0 \cdot 145)$. Other investigators $^{2627}$ found oral ketotifen to be significantly better than placebo in inhibiting allergen induced bronchoconstriction in adults and to be significantly more effective than clemastine in this respect. In our study the actions of ketotifen closely paralleled those of clemastine so ketotifen would appear to be acting primarily as a potent antihistamine. Antihistamines may exert their effect on allergen induced asthma by mechanisms additional to competitive antagonism of histamine. Many antihistaminic drugs will inhibit immunologically induced mediator release from human basophils and chopped human lung in vitro, at least at low concentrations. ${ }^{28} 29$

We have shown that inhaled clemastine can inhibit histamine induced airflow obstruction and is as effective as sodium cromoglycate at preventing allergen induced bronchoconstriction. Ketotifen appears to possess actions similar to those of clemastine with no additional "antianaphylactic" properties. Our studies, however, were performed with single doses of each drug and possibly clemastine and ketotifen would show different or additional pharmacological properties when administered in man over longer periods.

\section{References}

' Martin UL, Römer D. The pharmacological properties of a new, orally active anti-anaphylactic compound: ketotifen, a benzocycloheptathiophene. Drug Res 1978;28:770-82.

${ }^{2}$ Cairns H. Models for the development of anti-asthmatic drugs. In: Pepys J, Edwards AM, eds. The mast cell: its role in health and disease.Tunbridge Wells: Pitman Medical Co, 1979:172-7.

${ }^{3}$ Warner JO, Goldsworthy SJ. Comparative trial of ketotifen and clemastine in childhood seasonal allergic rhinitis and asthma. Res Clin Forums 1982;4:85-95.

${ }^{4}$ Salmon MA. Multicentre study for the evaluation of ketotifen in the prophylaxis of extrinsic asthma in children. Res Clin Forums 1982;4:45-51.

${ }^{5}$ Monie RDH, Smith AP, Leopold JD, Anderson EG, Davies BH, Thomas GO. Double-blind clinical trial of ketotifen and disodium cromoglycate in bronchial asthma. Thorax 1981;36:234 (abstract).

- Chai H, Farr RS, Froehlich LA, et al. Standardisation of 
bronchial inhalation challenge procedures. J Allergy Clin Immunol 1975;56:323-7.

${ }^{7}$ Siegel S. Non-parametric statistics. New York: McGraw-Hill Book Co, 1956.

${ }^{8}$ Juniper EF, Frith PA, Dunnett C, Cockcroft DW, Hargreave FE. Reproducibility and comparison of responses to inhaled histamine and methacholine. Thorax 1978;33:705-10.

${ }^{9}$ Rosenthal RR, Allen Bruce C, Lichtenstein LM, Norman PS. The role of inhalation challenge. Int Arch Allergy Appl Immunol 1975;49:89-94.

${ }^{10}$ Cockcroft DW, Ruffin RE, Dolovich J, Hargreave FE. Allergen-induced increase in non-allergic bronchial reactivity. Clin Allergy 1977;7:503-13.

" Phillips MJ, Meyrick Thomas RJ, Moodley I, Davies RJ. A comparison of the in-vivo effects of ketotifen, clemastine, chlorpheniramine and sodium cromoglycate on histamine and allergen induced weals in human skin. Br J Clin Pharm 1983;15:277-86.

12 Nogrady SG, Hartley JPR, Handslip PDJ, Hurst NP. Bronchodilatation after inhalation of the antihistamine clemastine. Thorax 1978;33:479-82.

${ }^{13}$ Partridge MR, Saunders KB. Effect of an inhaled antihistamine (clemastine) as a bronchodilator and as a maintenance treatment in asthma. Thorax 1979; 34:771-6.

${ }^{14}$ Curry JJ. The effect of antihistamine substances and other drugs on histamine bronchoconstriction in asthmatic subjects. J Clin Invest 1946;25:792-9.

${ }^{15}$ Kallos P. Laboratory and clinical investigations of the antihistamine clemastine (Tavegyl). Clin Trials $J$ 1971;8:23-6.

${ }^{16}$ Nogrady SG, Bevan C. Inhaled antihistaminesbronchodilatation and effects on histamine- and methacholine-induced bronchoconstriction. Thorax 1978;33:700-4.

${ }^{17}$ Mattson K, Poppius H, Nikander-Hurme R. Preventive effect of ketotifen, a new anti-allergic agent, in histamine-induced bronchoconstriction in asthmatics. Clin Allergy 1979;9:411-6.
${ }^{18}$ Weuthrich B, Radielovic P, Debelic M. The protective effect of a new anti-asthma agent (ketotifen, HC 20-511) against experimentally induced bronchospasm (5 different models). Int J Clin Pharmacol 1978;16:424.

${ }^{19}$ Cox JSG. Review of chemistry, pharmacology, toxicity, metabolism, specific side effects, anti-allergic properties in vitro and in vivo of disodium cromoglycate. In: Pepys J, Frankland W, eds. Disodium cromoglycate in allergic airways disease. London: Butterworths, 1970:13-25.

${ }^{20}$ Stokes TC, Morley J. Prospects for an oral Intal. Br J Dis Chest 1981;75:1-14.

${ }^{21}$ Kerr JW, Govindraj M, Patel KR. Effect of alphareceptor blocking drugs and disodium cromoglycate on histamine hypersensitivity in bronchial asthma. $\mathrm{Br}$ Med J 1970;ii:139-41.

${ }^{22}$ Kang B, Townley RG, Lee CK, Kolatkin BM. Bronchial reactivity to histamine before and after sodium cromoglycate in bronchial asthma. $\mathrm{Br} \mathrm{Med} J$ 1976;i:867-70.

${ }^{23}$ Karlin JM. The use of antihistamines in asthma. Ann Allergy 1972;30:342-7.

${ }^{24}$ Popa VT. Bronchodilating activity of an $\mathbf{H}_{1}$ blocker, chlorpheniramine. J Allergy Clin Immunol 1977; 39:54-63.

${ }^{25}$ Eiser NM, Mills J, Snashall PD, Guz A. The role of histamine receptors in asthma. Clin Sci 1981; 60:363-70.

${ }^{26}$ Craps L, Greenwood C, Radielovic P. Clinical investigations of agents with prophylactic anti-allergic effects in bronchial asthma. Clin Allergy 1978;8:373-82.

${ }^{27}$ Girard JP, Grevas M. Anti-asthmatic properties of a new peroral drug (HC 20-511). Acta Allergol (Kbh) 1977;32:27-34.

${ }^{28}$ Moodley I, Davies RJ. Inhibition and stimulation of mediator release from human leucocytes and chopped human lung by ketotifen. Clin Sci 1981;62:13-4.

${ }^{29}$ Church MK, Gradidge CF. Inhibition of histamine release from human lung in-vitro by antihistamines and related drugs. Br J Pharmacol 1980(a);69:663-7. 